\title{
El Derecho fiscal de las Corporaciones Locales españolas
}

En un artículo anterior sobre la sustantividad de las Haciendas locales (I), emplacé para posteriores trabajos el ocuparme del Derecho fiscal positivo español en relación con la administración local. La promesa y el empeño quisiera convertirlos en realidad, aun dándome cuenta de la difícil y enjundiosa tarea que ello supone. Dificultad que se manifiesta por la extensión de la materia a desarrollar y por la consiguiente labor de síntesis que la misma requiere en su exposición.

Por una cuestión metodológica y para mayor claridad, trataré por separado de la Hacienda provincial y de la municipal, y dentro de cada una, de su estructuración formal, de sus fuentes de ingresos, de sus motivos de gastos y de las garantías jurídicas y administrativas que la Ley establece. Aun cuando en breve síntesis, una justificación requiere la adopción de este método expositivo.

Toda Hacienda de una Corporación pública tiene dos aspectos: material o sustantivo, uno, formal o estructural, el otro. El primero de estos dos aspectos, es decir, el material, recoge aquello que es sustantivo con la existencia y razón de ser de la propia Entidad a que se refiere. Es preciso considerar que una Entidad pública no tiene en su esencia una finalidad de lucro, sino que es sustentadora de una idea, de un deber: la satisfacción de las necesidades colectivas que en su órbita de acción se produzcan. Para satisfacer esas necesidades colectivas tiene que disponer de medios

(1) "Las Haciendas locales", en Revista DE Estudios DE LA VIDA Local núm. 19. 
adecuados a las realidades en que las mismas se traduzcan, y como en último término vienen expresadas por índices materiales, medios de dicha índole será preciso recabar. Es decir, que la finalidad sustantiva de una Entidad pública se traduce en el orden material, en la existencia de una Hacienda en su sentido lato y vulgar, equiparable a la concepción amplia del patrimonio, o sea, conjunto de créditos y deudas, de ingresos y de gastos. Todo ello viene a expresarnos que ese aspecto material de una Hacienda pública está integrado por el conjunto de gastos necesarios a realizar para satisfacer las necesidades colectivas que se propone, y por los ingresos suficientes para cubrir aquellos gastos. Esta idea enlaza una consecuencia: los gastos han de preceder en su evaluación al cálculo de los ingresos, porque aquéllos son de naturaleza necesaria y los ingresos no son un fin, sino un medio; claro es, que los gastos tendrán un límite forzoso representado por la capacidad económica de la fuente de detracción de los ingresos. Este orden, lógico en una Hacienda autónoma o estatal, se quiebra en las Corporaciones locales españolas, que valúan antes los ingresos que los gastos, quizá por la parquedad de su capacidad económica independiente y la consiguiente rigidez apriorística de los ingresos.

Decimos que una Entidad pública tiene su "Hacienda" como medio para cumplir una finalidad; por ello necesita imperiosamente realizar su contenido con arreglo a un plan anterior y lógico. En otros términos aquel aspecto material o sustantivo precisa de una estructuración formal que le ordene y le supedite a su rigidez en garantía al cumplimiento de su propio fin. Pero como la materia sin la forma no tendría límites ni consistencia, y como la estructura es antecedente necesario para la obra, al precisar construir, y construir delimitando, necesitamos antes conocer la expresión, la estructura, para adentrarnos en el estudio de la materia. De aquí nuestra prioridad en tratar el Presupuesto antes del contenido material de la Hacienda.

Decimos que la Entidad pública no persigue objeto de lucro, sino que cumple fines impuestos por la comunidad que encuadra; pues bien, si su objeto es el servicio de los fines de esa comunidad, es evidente que en servicio de la misma debe dirigirse todo su es- 
fuerzo y acción. Este principio abstracto tiene una traducción real y práctica : los movimientos de la Corporación pública para la consecución de su objeto no son absolutamente libres, se encuentran autoritariamente reglados. Este problema, que trasladado al orden metafísico (¿quién los delimita?), supondría una solución, básica indudablemente, pero fuera de nuestro objeto, considerado desde el punto de vista fiscal y administrativo, supone la sumisión del desarrollo material y formal de la "Hacienda" a unas normas, a unas reglas, que son la expresión exacta de las garantías establecidas en favor de aquella comunidad cuyos fines trata de cumplir la Entidad pública al satisfacer las necesidades colectivas. Estas garantías, según el orden a que afecten, pueden tener diferentes expresiones, y así serán administrativas, jurídicas o económicas.

Con todo lo expuesto, pretendemos que brevemente quede expuesta la justificación de nuestro método, al considerar en el estudio del Derecho fiscal, la estructura de la "Hacienda", su aspecto material bifurcado en gastos e ingresos y las garantías de toda índole que para la gestión de la misma se establecen.

\section{LA PROVINCIA ESPAÑOLA Y SU DERECHO FISCAL}

Al hablar del Derecho fiscal de las provincias españolas sentimos, quizá más que en ningún otro caso, la necesidad de ordenar su exposición, y al intentar hacerlo consideremos, de acuerdo con nuestro sistema, las siguientes cuestiones por separado: el Presupuesto, los ingresos, los gastos y las garantías.

El Presupuesto

Reconocida por la doctrina, y contrastada en la práctica, la evidencia de que en las Corporaciones públicas al ejercer su actividad dinámica se producen fenómenos de orden económico, sin- 
tetizados en "ultima ratio" por la expresión de los gastos y la evaluación de los ingresos, se reconoce, asimismo, que uno de los principales problemas que las relaciones de unos y otros plantea, es el de llegar a la ecuación de los mismos. Situados en este punto de vista encontraremos fácilmente la justificación del Presupuesto, pues para llegar a establecer aquella ecuación buscada entre gastos e ingresos, será preciso contar con algún artificio que nos lo valore, calcule y acople; y este artificio o plan orgánico, en cuanto que se establece "a priori", constituye en esencia el Presupuesto. Es decir, que la estructuración formal de la Hacienda de una Entidad pública, se manifiesta en el orden legislativo, en el documento, estado o relación de gastos e ingresos, que recibe el nombre de Presupuesto. Su necesidad y su importancia, se desprenden de la propia necesidad e importancia que el orden tiene en la evaluación de los gastos e ingresos; y su significación no es otra, ni más ni menos, que aquella que acabamos de apuntar, pues pretender que el Presupuesto en sí tiene derivaciones de otra índole, es desenfocar el problema; desenfoque al que coadyuvan, indudablemente, el acto legislativo en el cual se suele contener, y el hecho de que en el mismo se comprendan, no sólo normas para su ejecución, sino a veces disposiciones generales y referentes, incluso, a otras cuestiones no estrictamente presupuestarias. Por ello nos ayudará grandemente a determinar la verdadera y estricta significación del Presupuesto, el despojarle de su empaque formal y el abstraerle de las disposiciones no referentes a su cálculo o ejecución. En las Corporaciones locales, ya nos lo encontramos independizado de su carácter de ley (puesto que aquellas Entidades no pueden dar disposiciones de semejante rango), y no por ello deja de ser un Presupuesto; lo cual nos demuestra que, si en algunos casos puede no revestir la forma de ley sin perder su carácter esencial, no hay motivo alguno para que por generalización de conceptos no podamos siempre abstraerle de aquella forma legal, ya que el aprobarle en forma de ley no puede tener otra significación, sino la de darle una mayor autenticidad, al propio tiempo que supone la realización más perfecta de un principio contrastado como esencial para toda la doctrina, cual es su publicidad; y así el Estado utiliza para su apro- 
bación el método más solemne que en el Derecho se conoce, pero ello sólo prueba la importancia del acto y no la consustancialidad con la forma. Esta necesidad de remarcar su trascendencia y de revestirle de la formalidad mayor, es lo que da lugar a la exigencia de un "quorum" especial para su aprobación en las Entidades locales, como más adelante veremos. Si a esta coincidencia unimos el hecho de que, aprovechando la forma legislativa en que el Presupuesto se aprueba, suelen contenerse en la misma ley algunas disposiciones, relacionadas con su desarrollo sí, pero independientes de su verdadera significación, encontraremos explicada suficientemente la postura de ciertos tratadistas (Jéze y Griziotti, por ejemplo), que intentan buscar en el Presupuesto aspectos distintos del único que él presenta. El Presupuesto no es nada más que un acto administrativo de evaluación de gastos e ingresos, y todo lo demás son cosas independientes a él. Su orientación obedecerá, ciertamente, a un criterio político determinado (Griziotti), pero este criterio político es anterior e independiente del Presupuesto, no es esencial con él, y lo prueba suficientemente el hecho de su variabilidad, sin que deje de ser el Presupuesto cálculo de gastos e ingresos.

Una vez realizada, a manera de preámbulo, esta breve justificación del significado técnico del Presupuesto con carácter general, y teniendo en cuenta que por lo que respecta a las administraciones locales, su significación no difiere en nada, y sí tan sólo su mecánica en cuanto a la confección, aprobación y justificación, estudiemos estos tres momentos por separado en la Hacienda provincial y con relación a los Presupuestos ordinarios.

A) Confeccion-Las Diputaciones provinciales están obligadas a formar en cada ejercicio económico (que coincide con el año natural), un Presupuesto ordinario para atender a todas sus obligaciones y servicios, así como para enjugar el déficit de ejercicios anteriores.

La formación de este Presupuesto comienza con la redacción del anteproyecto. La primera cuestión a dilucidar es quién redacta el anteproyecto, y aquí surge el primer problema interpretativo consistente en determinar qué disposición se encuentra en vigor a este 
respecto, pues si bien el Decreto-ley de I6 de junio de I93I, al derogar el Estatuto provincial de I925, dejó subsistente el título II de este último Cuerpo legal referente a la Hacienda provincial, no es menos cierto que el Decreto de 4 de diciembre del mismo año, contradijo en parte, y precisamente en la cuestión de que nos afecta dicho libro II o sus disposiciones complementarias, y, por lo tanto es preciso determinar si el Decreto de diciembre de I93 I está o no en vigor en esta cuestión. Nosotros entendemos que sí, en cuanto que al dar nuevas y diferentes normas a las que establecía el Reglamento de la Hacienda municipal, aplicable subsidiariamente $y$ en ausencia de preceptos concretos del libro II mencionado, es indudable que, a partir de aquella fecha, a sus preceptos y no a los del Reglamento de la Hacienda municipal hemos de atenernos, ya que además el mencionado Decreto no ha sido derogado expresamente, sino tan sólo contradecido en cuestiones concretas, y como la presente no se ha visto afectada por disposiciones posteriores a los preceptos del tan repetido Decreto de 4 de diciembre de I93I, nos acogeremos y, como consecuencia, concluiremos que el anteproyecto del Presupuesto de las Diputaciones provinciales será redactado por el Interventor de las mismas.

En la confección de este anteproyecto debemos observar, esencialmente, las cuestiones referentes a la época de su confección, a su estructura y al sistema evaluatorio seguido.

a) Epoca de confección.-El Decreto de I93I, antes mencionado, nada dice a este respecto, pero sí el Reglamento de la $\mathrm{Ha}$ cienda municipal que establece unos plazos muy anticipados (comienzan en ro de junio), difíciles de observar y prácticamente inobservados por las Corporaciones respectivas. Sin embargo, existe un plazo, que es el esencial, como se reconoce por la O. M. de I 5 de noviembre de 1940 reiterada anualmente, y que en la actualidad se fija en el 25 de noviembre, fecha máxima en la cual debe ser sometido a la Comisión Gestora para su estudio. Por lo tanto, antes de dicho día 25 de noviembre deberá estar terminado el proyecto de Presupuesto, que se ha redactado por la Comisión de Ha- 
cienda (2), tomando como base el anteproyecto formulado por el Interventor.

b) Estructura.-Con relación a este problema, el Estatuto provincial sólo nos deja entrever su exigencia de la unidad presupuestaria en cuanto que al prohibir los presupuestos adicionales (artículo 199), no permite, indudablemente, los presupuestos específicos con la salvedad indudable de aquellos que por su índole tuvieran el carácter de extraordinarios.

Ante esta carencia de regulación en el texto principal, trataremos de encontrar disposiciones que, con carácter complementario, regulen la materia, y así hemos de tener en cuenta la $O$. M. de I2 de mayo de 1925 que, con carácter "provisional", fijó una estructura para los Presupuestos provinciales, cuya provisionalidad sigue vigente en la actualidad, como lo demuestra la práctica constante de las diferentes Corporaciones, y que es la siguiente:

El Presupuesto se divide en dos grandes Secciones, de Ingresos y de Gastos, cada una de las cuales, a su vez, se divide en 19 capítulos, y éstos en artículos y conceptos, llevando estos últimos numeración correlativa para cada sección de Ingresos y de Gastos. La denominación de los i9 capítulos de Ingresos o Gastos son, respectivamente, las siguientes:

a') INGResos:

Capítulo I. ${ }^{\circ}$-Rentas.

“ $\quad 2{ }^{\circ}$ - -Bienes provinciales.

" $\quad 3{ }^{\circ}$ - - Subvenciones y donativos.

" $\quad 4{ }^{\circ}$--Legados y mandas.

" $5 .^{\circ}$ - Eventuales, extraordinarios e indemnizaciones.

" $\quad 60^{\circ}$-Contribuciones especiales.

" $\quad 70^{\circ}$-Derechos y tasas.

" $\quad 80^{\circ}$-Arbitrios provinciales.

" $\quad 9{ }^{\circ}$.-Impuestos y recursos cedidos por el Estado.

" ro.-Cesiones de recursos municipales.

" II.-Recargos provinciales.

(2) Compuesta por la mitad, menos umo, de los Vacales que constituyen la Comisión Gestora. (Decreto de 4 de diciembre de 1931). 
Capítulo 12.- Traspasos de obras y servicios públicos.

" 13.-Crédito provincial.

" I4.-Recursos especiales.

" I 5.-Multas.

" 16.-Mancomunidades interprovinciales.

I7.-Reintegros.

" $\quad$ 8.-Fianzas y depósitos.

" I9.-Resultas.

b') Gastos:

Capítulo r. ${ }^{\circ}$-Obligaciones generales.

" $\quad 20^{\circ}$.- Representación provincial.

" $\quad 3{ }^{\circ}$. - Vigilancia y seguridad.

" $\quad 4{ }^{\circ}$ - - Bienes provinciales.

" $\quad 5{ }^{\circ}$.-Gastos de recaudación.

" $\quad 6 .^{\circ}$-- Personal y material.

" $\quad 70^{\circ}$ - - Salubridad e higiene.

$" \quad 80^{\circ}$--Beneficencia.

" $\quad 90^{\circ}$.-Asistencia social.

" IO.-Instrucción pública.

" I I.-Obras públicas y edificios provinciales.

" I2.-Traspaso de obras y servicios públicos del Estado.

" I3.-Montes y pesca.

" I4.-Agricultura y ganadería.

" I5.-Crédito provincial.

" I6.-Mancomunidades interprovinciales.

" I 7.-Devoluciones.

" I 8.-Imprevistos.

" I9.-Resultas.

-Una observación es forzoso realizar, y es la alteración del orden, incluso el general, en relación con los Presupuestos del Estado, que tratan, en primer término, de los Gastos (estado letra A), y luego de los Ingresos (estado letra B). No hablemos ya del contenido de cada una de las dos Secciones antedichas que es esen- 
cialmente diverso, debido a la índole totalmente diferente de las Entidades a que cada presupuesto se refiere y a la finalidad que las mismas se proponen.

Puede ocurrir, por último, que en alguna Corporación provincial no existiera motivo de ingreso o de gasto por el concepto de alguno o algunos de los capítulos antes enunciados, en cuyo caso no se cubriría et mismo, pero sin alterar por ello su numeración y orden, pues una finalidad esencial de esta estructura uniforme, son los fines estadísticos.

c) Sistema evaluatorio.-En cualquier clase de presupuestos que tratemos de estructurar, se presentará un problema básico enunciado así: si el Presupuesto es un cálculo apriorístico de gastos e ingresos ¿ cómo procederemos a realizar el de unos y otros?

Respecto a los gastos, el cálculo será relativamente sencillo, pues la única dificultad estará en su reducción y acoplamiento a los ingresos posibles. El peligro y la dificultad estará precisamente en la fijación de los ingresos, pues si la realizamos con un recelo exagerado, podernos dejar indotadas y no cubiertas algunas necesidades de carácter general, cuando en realidad la economía consiguiente tenía vitalidad bastante para satisfacerlas; pero si, por el contrario, realizamos un avalúo de los ingresos con exagerado optimismo, caeremos en el defiecto mucho más grave de dejar en descubierto la satisfacción de gastos que sobre una base falsa habíamos previsto realizar, trayendo como consecuencia un desequilibrio presupuestario, reflejo de una economía débil en proporción a la presión tributaria a que se la quiso someter.

Por la realidad evidente de estos problemas apuntados, se ha preocupado siempre la doctrina, procurando fijar un método o sistema de evaluación de los ingresos en la confección de un presupuesto perfecto. Si prescindimos de exponer la multitud de posiciones particularistas y tratamos de sistematizar las mismas polarizándolas hacia sus extremos, veremos dibujados perfectamente dos sistemas evaluatorios que en esencia consisten en lo siguiente: uno de ellos quiere cimentarse en el cálculo apriorístico de la realidad económica de la entidad cuyo presupuesto se trata de estruc. turar; se fija en su vitalidad, en su producción posible, en la co- 
yuntura, en su situación psicológica, es decir, en todos los factores que directa $o$ indirectamente pueden influir durante el lapso de tiempo a que se contrae el cálculo para conseguir un mayor rendimiento impositivo; este sistema, no cabe duda que bien realizado, consigue una exactitud ideal, pero requiere tal fuerza de penetración, tal sagacidad en el cálculo y tal sinceridad en su cumplimiento, que fácilmente puede llevarnos a un fracaso, siendo por ello esencialmente peligroso. $\mathrm{El}$ otro sistema tiene una preocupación fundamental: evitar ese peligro, ese riesgo y esa eventualidad que el anterior supone, asegurándose, aun a costa de un cálculo erróneo por defecto, la seguridad de una nivelación $y$, al ser posible, de un superávit real presupuestario. Esto lo consigue con la valoración de los ingresos según los rendimientos obtenidos efectivamente en el último ejercicio liquidado, lo cual, teniendo en cuenta el crecimiento normal de la productividad, nos asegura un margen evidente de seguridad en el cálculo.

Es evidente, que en la práctica no se suele emplear ninguno de los dos anteriores sistemas en su integridad, por excesivamente alegre, el uno, y por cauteloso, en extremo, el otro. Sin embargo, el Estatuto provincial, en su artículo 194, no duda en adscribirse íntegramente al segundo de los sistemas antes enunciados, quizá porque considere preferible un exceso de prudencia en el cálculo de los ingresos de estas Entidades que no tienen en realidad una economía propia e independiente con la necesaria fortaleza para tolerar errores de apreciación. Sin embargo, un motivo de apartamiento de la rigidez anterior deja entrever cuando exista una alteración de tarifas o por la existencia de "causas excepcionales que justifiquen la previsión de un mayor importe", pero, en este último caso o cuando se trate de ingresos nuevos, se recomienda anualmente moderación a través de las normas que reitera con esa periodicidad la Dirección General de Administración local. Lo que desde luego no podrá confeccionarse ningún presupuesto, es con déficit inicial por prohibirlo expresamente el art. I93 del Estatuto.

B) Aprobacion.--Realizado por la Comisión de Hacienda el proyecto de presupuesto, según el anteproyecto redactado por el Interventor, y de acuerdo con las normas evaluatorias y estructura 
antes dadas, se someterá dicho proyecto a la aprobación de la Comisión Gestora acompañado de los documentos que el art. 296 del Estatuto municipal determina, y con base del cual la Comisión Gestora formará el Presupuesto definitivo, que deberá ser aprobado por mayoría absoluta de los componentes de la misma (3). Ahora bien, una vez así aprobados los presupuestos, no tendrán efectividad hasta que cumplan ciertos requisitos de publicidad y sanción que seguidamente exponemos:

a) Publicidad.-Dice el art. 200 del Estatuto provincial, que el Presidente de la Diputación "insertará en el Boletín Oficial un resumen por capítulos y artículos" del Presupuesto. Esta exigencia, que es consecuencia de un axioma doctrinal universalmente reconocido, y manifestación esencial de las garantías que el legislador ofrece al administrado, tiene como finalidad primera el facilitar la impugnación del Presupuesto por posible lesión del mismo para los intereses provinciales, municipales o particulares, y así se reconoce este derecho de alzada a los Diputados provinciales (hoy Gestores), a los Ayuntamientos y a cualquier particular interesado.

b) Impugnación.-Al tratar de esclarecer en toda su plenitud el derecho y el procedimiento de impugnación del Presupuesto provincial, nos encontramos con un problema provio de vigencia de disposiciones (como en la mayor parte de la vida local ocurre), que tiene una cierta importancia por suponer regulación diversa en un caso y en otro. El problema viene a reducirse a la siguiente cuestión: ¿están en vigor hoy día las disposiciones del Decreto de 4 de diciembre de I93I? Más arriba, y al hablar de la confección del Presupuesto, nos pronunciamos por su vigencia en lo que a aquella cuestión concreta se refería; pero ahora bien, en aquel caso no había dificultad en admitirla en cuanto que hay una ausencia de regulación específica en el Estatuto provincial, y al aplicar normas subsidiarias, lógico es que se apliquen las más recientes y específicas cuando ellas no están d'erogadas expresamente. Pero en el presente caso de la impugnación del Presupuesto, no ocurre lo propio, ya que la regulación del Estatuto provincial, hoy indiscutiblemente en

(3) Vemos en esta breve exigencia una manifestación evidente de la salvagruandia que el ilegislador realiza de los principios esenciales del Presupuresto. 
vigor (4), es esencialmente distinta de la del Decreto citado de I93I, por lo que estimamos debe considerarse únicamente en vigor el Estatuto, que regula la materia en los artículos 200 al 203 , sin que haya lugar, por lo tanto, a los recursos económico-administrativo y contencioso-administrativo en los casos específicos en que los artículos $8 .^{\circ}$ y $9 .^{\circ}$ del mencionado Decreto de 4 de diciembre de 193 I los admitían.

c) Sanción.-Con objeto de que el Presupuesto sea autorizado debidamente, el Presidente de la Diputación está obligado a remitirlo al Gobernador civil dentro de los cinco días siguientes a haber sido aprobado por la Corporación. El Gobernador puede sancionar sin más los Presupuestos correspondientes, o puede enervar la validez de los mismos, elevándolos al Ministerio de la Gobernación que resolverá en definitiva. Tanto en un caso como en otro, el Gobernador puede asesorarse para tomar su resolución, del Jefe de la Sección provincial de Administración local y de cuantas autoridades lo crea necesario.

Para no aprobar el Presupuesto de por sí, el Gobernador se basará en alguno de los siguientes motivos:

I. Por causas ajenas a su autoridad, siempre que existan reclamaciones.

2. ${ }^{\circ}$ Por causas dependientes de su autoridad, si advierte:

$\left.a^{\prime}\right)$ extralimitación legal,

$\left.b^{\prime}\right)$ insuficiencia de recursos, o

$\left.c^{\prime}\right)$ perjuicio para los intereses del Estado.

C) Justificacion.-Bajo este epígrafe, hacemos referencia, no a la razón de ser o de existir del Presupuesto, sino a la necesidad de dar cuenta de su administración, es decir, de la inversión de sus consignaciones y de la percepción de sus ingresos. Esta función participa del carácter de garantías que la Administración concede a los administrados y de las que nos ocuparemos en lugar oportuno.

El Presupuesto, que es aquella evaluación estática de gastos e ingresos, de la que antes hablábamos, al contrastarse con la reali-

(4) Comprabar el art. I. ${ }^{\circ}$ de lo O. M. de 3 de noviembre de 1939 , reiterada anua"mente. 
dad, toma vida y refieja una groyección dinámica a trarés de todo el período de su vigencia. De esta traducción dinámica de su energía potencial, es precisamente de lo que, aqueilos funcionarios a cuyo cargo está la aplicación del Presupuesto, están obligados a dar cuenta, y ásí lo reconoce el Estatuto provincial en su art. 295. Toda esta justificación de la inversión presupuestaria se hace posible por la obligación en que se encuentran las Corporaciones provinciales de adaptar su vida económica a una determinada contabilidad, de cuyo desenvolvimiento nos ocuparemos más adelante al tratar de las garantías.

D) Presupuestos extraordinarios.-No quedaría completa esta breve exposición que hemos realizado del Presupuesto provincial español, si no hiciéramos, cuando menos, una alusión a los llamados extraordinarios.

Sabido es que una de las clasificaciones que del Presupuesto con carácter general se realiza, es aquella que los distingue en ordinarios y extraordinarios; diferencia que habremos de buscar, no solamente en razón de la época a que se refieran, sino de una manera esencial por el motivo que los justifique, es decir, por la finalidad o esencia del gasto a que traten de atender. Así cuando una Entidad pública tiene una necesidad singular a la que hacer frente, recurre a la confección de un presupuesto extraordinario, que por referirse a gastos anómalos, se nutrirá también con ingresos no comunes ni periódicos. $Y$ en este sentido observamos las disposiciones de los párrafos $1 .^{\circ}$ y $3 .^{\circ}$ del art. 198 del Estatuto provincial (5), de los que se desprende aquel concepto de atenciones imprevistas para los gastos y la vocación a recursos extraordinarios en cuanto

(5) Art. 198.- "Cutando para cubrir atenciones imprevistas, para satisfacer deudas o para cualquier otro objeto de importancia, no determinado en el Presupuesto ordinario, sean insuficientes las recunsos consigniados, se fonmará un Presupuesto extraondinario, con dotación efectiva y cabal, en la misma forma y por el mismo procedimiento que el ordinario.

Quada terminantemente prohibido enjugar el déficit de ejercicios ordinarios par medio de presúpuestos extraondinarois y empréstitos.

En el caso de que fuese condenaida la provincia al pago de cantidad, la Diputación, después de ejecutoriada la stentencia, procoderá a formar y dotat cumplidamente un pnssupuesto extraordinario, a no ser que el acreedor comvenga en aplazar el cobro, de modo que puedan consignarse en presupuestos ordinarios sucesivos las sumais necesarias." 
a los ingresos, en la interpretación a "sensu contrario" de la insuficiencia de los recursos consignados en el Presupuesto ordinario. Ahora bien, ¿cuáles pueden ser aquellas "atenciones imprevistas" y cuáles estos "recursos extraordinarios"? En cuanto a las primeras, algunas se consideran en el Estatuto, cuales son la satisfacción de deudas o el pago de cantidad como consecuencia de condena por los Tribunales; pero esta enunciación no puede tomarse como "numerus clausum", y así se desprende del propio texto legal que habla de "cualquier otro objeto de importancia"; pero, ahora bien, una prohibición expresa se señala: la de enjugar el déficit de ejercicios ordinarios. Por lo tanto, podemos concluir que, exceptuando este último caso, cualquier atención de tipo extraordinario puede cubrirse con estos Presupuestos, pues si alguna prohibición más hubiera querido agregar el legislador, es presumible que lo habría consignado expresamente, además de que siempre queda expedito el freno de la Autoridad central, por medio de su imprescindible aprobación, como luego veremos. $Y$, por último, en cuanto a la fuente de ingresos, es evidente que deberá estar constituída por aquellos que no deban reflejarse en el Presupuesto ordinario por su regularidad y periodicidad, pues como expresa la Dirección General de Administración local, en su circular de 3 I de enero de 1929 , si los presupuestos extraordinarios se nutriesen con la existencia de Caja, o con el excedente de los ingresos ordinarios, es evidente que se dispondría de recursos específicamente pertenecientes al presupuesto ordinario, confundiendo ambos presupuestos y procediendo en contra de los preceptos del art. 296 del Estatuto provincial y del artículo I I del Reglamento de la Hacienda municipal, aplicable en este caso.

En cuanto a la tramitación de estos presupuestos, se siguen normas análogas a las de los ordinarios, con la salvedad, antes apuntada, de que aquí es imprescindible la aprobación por el Ministerio de la Gobernación y el informe favorable del de Hacienda, estimando nosotros, por lo tanto, que no afecta a estos presupuestos 10 establecido en el art. 202 del Estatuto provincial, en cuanto a aplicación del silencio administrativo.

(Continuara.)

GABRIEL DE USERA. 